\title{
Effect of Bee Honey on Blood Glucose Level of Sudanese Patients with Type 2 Diabetes
}

\section{Mellitus}

\author{
Samia Mahdi Ahmed* \\ Department of Medical Laboratory Technology, Faculty of Applied Medical Sciences, Taibah University, AL Madinah, Kingdom of Saudi Arabia
}

*Corresponding author: Samia Mahdi Ahmed, Department of Medical Laboratory Technology, Faculty of Applied Medical Sciences, Taibah University, AL Madinah, Kingdom of Saudi Arabia, E-mail: samiamahdiahmed@yahoo.com

Received: 06 Nov, 2020 | Accepted: 18 Feb, 2020 | Published: 24 Feb, 2020

Citation: Ahmed SM (2020) Effect of Bee Honey on Blood Glucose Level of Sudanese Patients with Type 2 Diabetes Mellitus. J Diab Res Ther 6(1): dx.doi.org/10.16966/2380-5544.151

Copyright: (C) 2020 Ahmed SM. This is an open-access article distributed under the terms of the Creative Commons Attribution License, which permits unrestricted use, distribution, and reproduction in any medium, provided the original author and source are credited.

\begin{abstract}
This study was held to determine the effect of bee honey on blood glucose level of newly discovered Sudanese type-2 diabetic patients (non-insulin dependent) and compared with healthy controls. Forty one diabetic patients and 10 healthy non diabetic volunteers agreed to take part in the study. Specific doses of honey or a mixture of sugars that represents the main sugars in honey (fructose, glucose, sucrose) in the same proportions as that found in the honey sample were used. Glucose doses were also given, and the effects on blood glucose levels were compared with honey and sugars mixtures. Blood glucose levels were measured at 0, 60, 120, and 180 min intervals.

Honey and sugars mixtures at high doses (75 g) gave comparable or similar levels of glucose in the blood. After 2 and 3 hours, blood glucose dropped slightly but still higher than the fasting level. However, giving honey and sugars mixture at low doses $(25 \mathrm{~g})$ did not cause significant rise in blood glucose after 1 hour, and the blood glucose level dropped below the fasting level after 3 hours ( $p=0.051$ and 0.019 for the honey and the sugars mixtures respectively). Glucose doses were given as $50 \mathrm{~g}$ or $25 \mathrm{~g}$ to diabetic patients and to the healthy controls and the blood glucose levels were determined as mentioned above. The comparison of the blood glucose levels, after giving honey (equivalent to $75 \mathrm{~g}$ sugars), sugars mixture (75 g), or glucose $(50 \mathrm{~g})$ showed that the glucose resulted in sharp peak after 1 hour which remained high 2 hours later as compared to honey and sugars mixtures.

Comparing the effects of low doses of honey (equivalent to $25 \mathrm{~g}$ sugars), sugars mixture ( $25 \mathrm{~g}$ ), and glucose ( $25 \mathrm{~g}$ ); it was found that both honey and sugars mixtures did not raise the blood glucose level significantly, up to 3 hours; whereas the dose of glucose alone gave sharp rise after 1 hour and remained relatively higher than the levels obtained by honey and the sugars mixtures. As conclusion, low doses of pure honey, approximately 3 table spoons can be recommended as a sweetener for diabetic patients instead of using the so-called diabetic food which often have side effects and with no nutritional value.
\end{abstract}

Keywords: Bee honey; Diabetes type 2; Blood glucose; Diabetic Sudanese

\section{Introduction}

Diabetes Mellitus (DM) is an endocrinological disorder [1]. It is a group of metabolic disorders resulting from an abnormality in insulin secretions, insulin action, or both. Lack of, or reduced insulin will lead to high blood glucose and glucose intolerance [2]. Type 2 diabetes includes individuals who have insulin resistance and usually have relative (rather than absolute) insulin deficiency. Diabetes has many serious complications and may lead to mortality.

Bee honey is a natural food produced by honey bee; it is usually used as a sweetener. Also, it is known for its curative value [3] it was being used as traditional medicine to cure many health problems, diabetes may be one of them. Honey contains many compounds such as sugars, mainly fructose $(\sim 38 \%)$, glucose $(\sim 31 \%)$ and sucrose $(\sim 1 \%)$. Moreover, honey contains minerals, proteins, several vitamins (niacin, riboflavin, pantothenic acid, folate, pyridoxine, and vitamin C), enzymes (such as catalase, reduced glutathione, superoxide dismutase), flavonoids, and phenolic acids $[4,5]$. Bee honey was found to have many medicinal effects, these include anti-inflammatory [6], anti-fungal [7], anti-viral [8], antibacterial [9], and antitumor [10].

\section{Methods}

\section{Honey sample}

Honey sample was brought from Raja (Bahr El-Gazal) in the South of Sudan, hand to hand delivery from honey collector. The price of table sugar in Raja was higher than honey (so it is unlikely to be adulterated). Honey sample was analyzed [11] to test its genuineness and to specify the main sugars. The following were assessed: $\mathrm{pH}$, free acidity, total acidity, Hexamethylfurfal (HMF), moisture content, and percentages of fructose, glucose, and sucrose. Reagents were purchased from The British Drug Houses Ltd, BDH Laboratory Chemicals Groups, Poole England.

\section{Subjects}

All volunteers were fully informed by the aim of the study. Written 
informed consents were obtained from all individuals. Clinical examination was done and data recorded. Apparently ill patients were excluded from the study as well as patients with complications or physical disabilities. Forty one Sudanese newly discovered type 2 diabetic patients were enrolled in this study as well as 10 healthy controls (5 males, aged 29-57 years; 5 females, aged 28-50 years). Patients and healthy controls were divided into 3 groups:

Group 1: 29 patients (15 males aged 30-67 years; 14 females aged $24-57$ years)

Group 2: 21 patients (5 males aged 30-59 years; 16 females aged 24-60 years)

Group 3: 10 patients (4 males aged 30-49 years; 6 females aged 4060 years)

Since all the patients were newly diagnosed as diabetics, HbAlc was measured to determine the level of control on first presentation.

\section{The Tests}

\section{Subjects were involved in 3 tests}

In the first test, 29 patients were given $108 \mathrm{~g}$ of honey (containing $75 \mathrm{~g}$ of sugars) after taking fasting blood samples. Further blood samples were taken after 60,120 , and 180 minutes to determine the blood glucose levels. A week later, the same test was repeated with an equivalent dose, i.e., a total of $75 \mathrm{~g}$, of sugars mixtures (fructose $41 \mathrm{~g}$, glucose $30.8 \mathrm{~g}$, sucrose $3.2 \mathrm{~g}$ ) instead of honey and blood glucose levels were determined at the time intervals mentioned above.

In the second test, a dose of honey was given ( $36 \mathrm{~g}$, which contained $25 \mathrm{~g}$ sugars), or $25 \mathrm{~g}$ of sugars mixture (containing $13.7 \mathrm{~g}$ fructose, 10.3 g glucose, and $1.1 \mathrm{~g}$ sucrose) were repeated on 21 diabetic patients.

In the third test, glucose doses were given to 10 patients as $50 \mathrm{~g}$ or $25 \mathrm{~g}$ to diabetic patients, then blood glucose levels were determined as mentioned above.

Involvement of patients in each test was according to circumstances surrounding the patients since some of them started the test and then apologized (left). The 10 healthy controls were involved in every test. All doses (honey or sugars were given orally after being dissolved in about $300 \mathrm{ml}$ of water.

Blood samples $(5 \mathrm{ml})$ were collected from all subjects (before doses of honey or sugars were given) and divided intofluoride/oxalatecontaining vials and lithium/heparin-containing vials to determine the levels of fasting blood glucose and Glycatedhemoglobin (HbA1c) respectively. Plasma glucose was measured using MERCK MEGA analyzer system.

HbAlc was measured by micro column chromatography (using commercial kit) followed by photometry (reagents purchased from Biosystems Reagents and Instruments, Spain).

Data analyzed using analysis of variance. Differences among means determined for significance at $5 \%$ level using T-test and SPSS computer program.

\section{Results}

Honey sample was found to be genuine (Tables 1and 2) according to the global reference values.

\section{HbA1C results}

Results obtained (Table 3) showed that $92 \%$ of the patients had high values of HbAlc, which indicates that Sudanese people do not develop
Table 1: Analysis of Honey Sample.

\begin{tabular}{|l|c|}
\hline \multicolumn{1}{|c|}{ Parameter } & Result \\
\hline $\mathrm{pH}$ & 4.64 \\
\hline Free acidity & $63.2 \mathrm{meq}$ Acid/Kg \\
\hline Total acidity & 69.4 meq Acid/Kg \\
\hline Hexamethylfurfal (HMF) & Negative (genuine honey has no or low HMF) \\
\hline Moisture content & $19.8 \%$ \\
\hline
\end{tabular}

Table 2: Sugar percentages in the honey sample.

\begin{tabular}{|l|c|}
\hline \multicolumn{1}{|c|}{ Sugar } & Ratio \% \\
\hline Fructose & 38.0 \\
\hline Glucose & 28.5 \\
\hline Sucrose & 3.0 \\
\hline Fructose/Glucose & $133 / 100$ \\
\hline
\end{tabular}

Table 3: HbA1c Results (reference value 4.2-6.2 \%).

\begin{tabular}{|c|c|}
\hline No of patients & Percentages \\
\hline 1 & 5.4 \\
\hline 2 & $6.5,6.9$ \\
\hline 38 & $\geq 9.2$ \\
\hline
\end{tabular}

the habit of contacting the doctor until the disease reaches a critical stage.

Comparison of the results of the above tests (regarding honey or sugar doses), results showed that, honey and sugars mixtures at high doses (75 g) gave comparable or similar levels of glucose in the blood ( $p>0.05$ ). After 2 and 3 hours; blood glucose dropped slightly but still higher than the fasting level (Figures 1 and 2).

The comparison of the blood glucose levels, after giving honey (equivalent to $75 \mathrm{~g}$ sugars), sugars mixture $(75 \mathrm{~g})$, or glucose $(50 \mathrm{~g})$ showed that the glucose resulted in sharp peak after 1 hour which remained high 2 hours later as compared to honey and sugars mixtures (Figures 3 and 4).

However, giving honey and sugars mixture at low doses (equivalent to $25 \mathrm{~g}$ ) did not give sustained high blood glucose level after 3 hours (Figures 5 and 6), instead there was a significant drop in blood glucose levels as compared to the fasting level $(\mathrm{p}=0.051$ and 0.019 for the honey and the sugar respectively). Data obtained from the healthy controls also showed that both honey and sugars mixtures raised the blood glucose level reaching a peak at 60 minutes and then dropped below the fasting level after 3 hours (Figures 7 and 8).

When comparing the effects of low doses of honey (equivalent to 25 g sugars), sugars mixture (25 g), and glucose ( $25 \mathrm{~g})$; it was found that both honey and sugars mixtures did not raise the blood glucose level significantly, up to 3 hours; whereas the dose of glucose alone gave sharp rise after 1 hour and remained relatively higher than the levels obtained by honey and the sugars mixtures (Figure 9).

\section{Discussion}

Diabetes mellitus is one of the most common diseases throughout the world. Diabetic patients suffer a lot from this disease and its complications. Control of the disease which may be by diet alone, diet and oral hypoglycemic drug, or diet and insulin is not an exclusive treatment. In addition, they have some disadvantages such as the side effects of the oral hypoglycemic. Also, accidental insulin over dosage or failure to eat after insulin may lead to hypoglycemia. Moreover to 


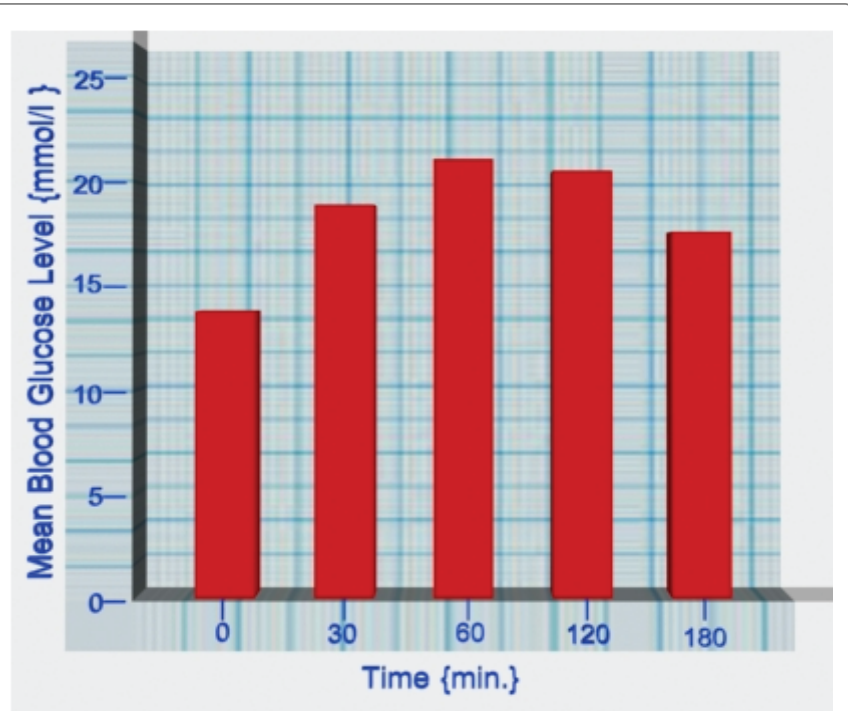

Figure 1: Mean Blood Glucose Level (mmol/l) in Diabetic Patients after a Dose of Honey Equivalent to 75 grams of Sugars $(n=29)$.

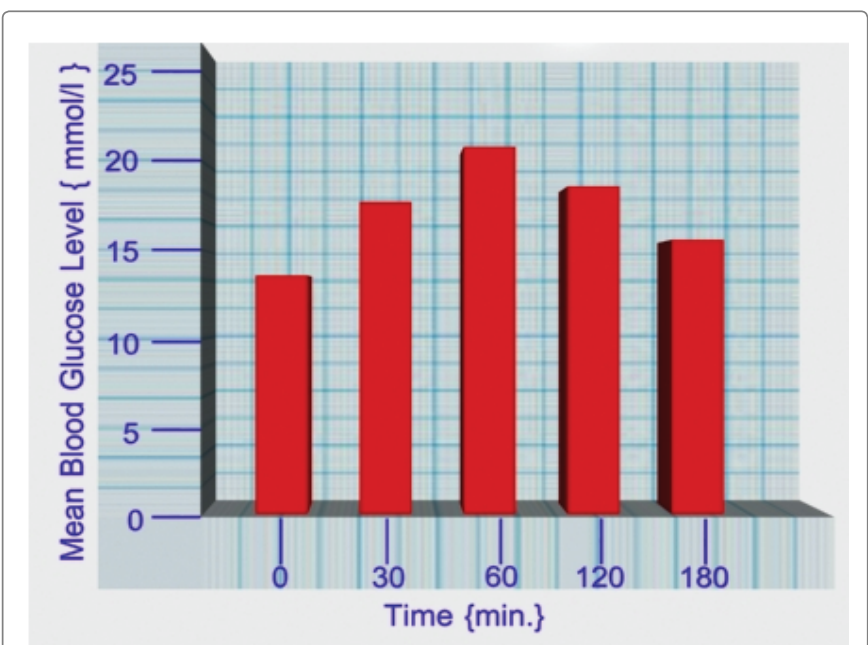

Figure 2: Mean Blood Glucose Level $(\mathrm{mmol} / \mathrm{l})$ in Diabetic Patients after a Dose (75 grams) of Sugars Mixture $(n=29)$.

put a patient under restricted diet prevent the patient from nutrients which are needed by the body, especially, if the diabetic patient suffers from other diseases; for example, to lessen the risk of cardiovascular diseases, American, Canadian, and British Diabetes associations have recommended increasing the carbohydrates intake by diabetic patient. They have agreed on the point that food which raises blood glucose level least for a given content, are most suitable [12].

Bee honey is rich in different nutrients especially carbohydrates, and has a great curative value known to mankind since ancient times. In our study, the effect of bee honey on blood glucose level in newly discovered patients was conducted. All high doses of honey or sugars mixtures (equivalent to 75 grams), or the glucose doses (50 grams and 25 grams) raised the blood glucose level and did not drop to the fasting level after 2 and 3 hours. Unlike the low doses of honey or sugars mixtures (equivalent to 25 grams), they did not cause significant rise in blood glucose after 1 hour, and the blood glucose level dropped below the fasting level after 3 hours.

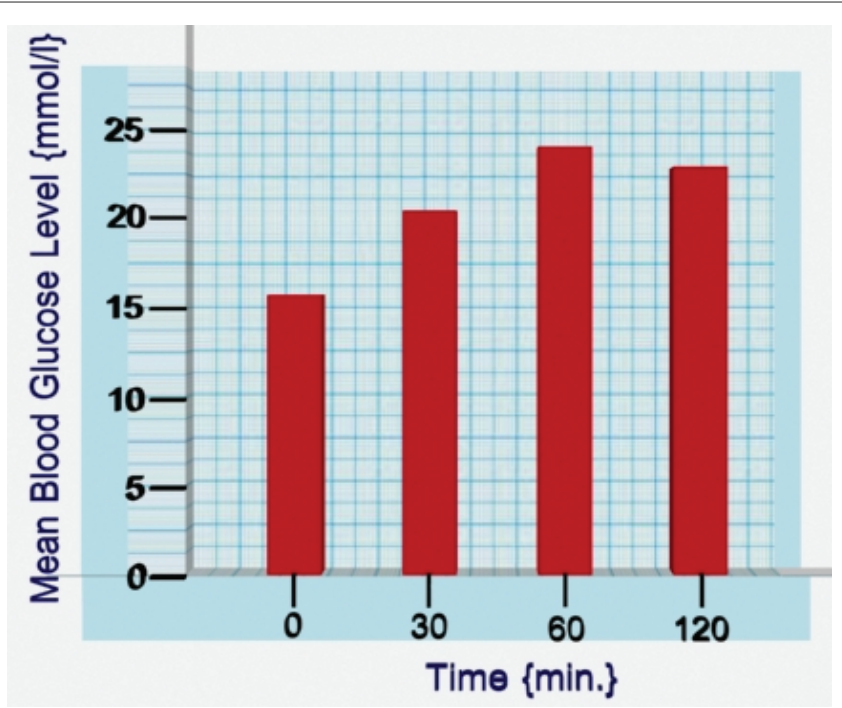

Figure 3: Mean Blood Glucose Level (mmol/l) in Diabetic Patients after a Dose of 50 grams of Glucose $(n=15)$.

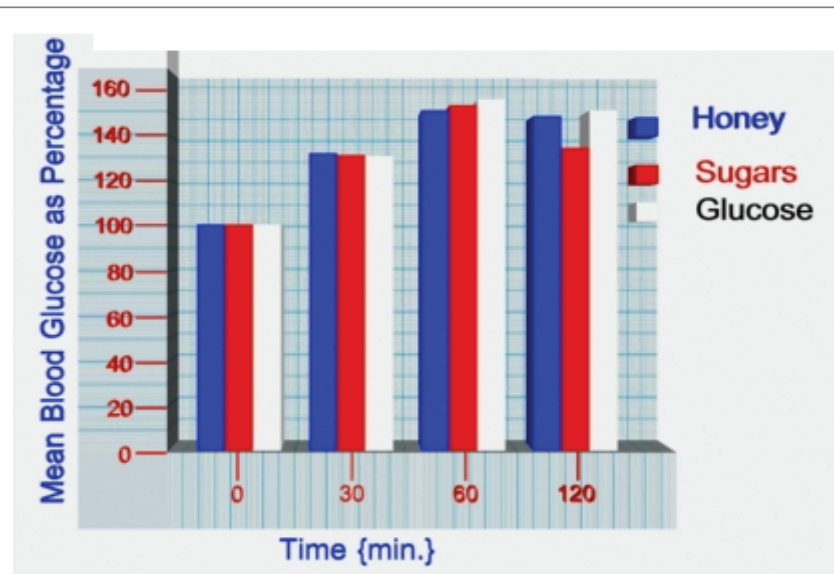

Figure 4: Mean Blood Glucose Level as Percentage (Fasting=100\% Comparing High Dose of Honey (75 grams), High Dose of Sugars Mixture (75 grams), and Glucose Dose (50 grams).

Honey is known to have high fructose content compared to glucose. Generally, fructose has only a small direct stimulatory effect on insulin secretion, but insulin does not promote its uptake into tissue [13]; instead tissue fructose uptake is proportional to the plasma fructose level. Fructose when found in a mixture with glucose enhances the metabolism and utilization of the latter [14]. Fructose activates glycogen synthetase and inhibits phosphorylase which involved in glycogen degradation [15] hence allowing a net reduction in glucose output. Thus, fructose may help in hepatic glucose uptake and glycogen synthesis.

In spite of those advantages, but taking pure fructose in large amount for long time may disrupt blood lipids mainly triglycerides [16,17]. Moreover, large doses of fructose may cause hyperuricemia [17]. Moreover, comparing honey to the so called 'diabetic food' honey is rich in nutrients (e.g proteins, amino acids, minerals, vitamins, organic acids, and others). Honey contains enzymes such as amylase that converts starch and dexrin into simple sugars; 
sucrase which converts sucrose into fructose and glucose as well as other enzymes. Combination of vitamins: thiamin, ascorbic acid, and nicotinic acid with fructose in honey can have a beneficial effect on normalizing the conversion of carbohydrates in diabetics since these vitamins also lower the sugar levels of blood. Also, honey was found to have substances akin to insulin [18]. Moreover, honey is found to have many other effects such as antihypertensive $[19,20]$ cardioprotective [21], hepatoprotective [22] and antioxidant $[23,24]$ effects.

Thus, bee honey is useful for diabetic patients as a tasty substance and as a nutritious substance. Honey may have a role in diabetic complications, so more effort is needed to be exerted in this field $[25,26]$.

The importance of bee honey was mentioned in the Holy Quran more than 1440 years ago:

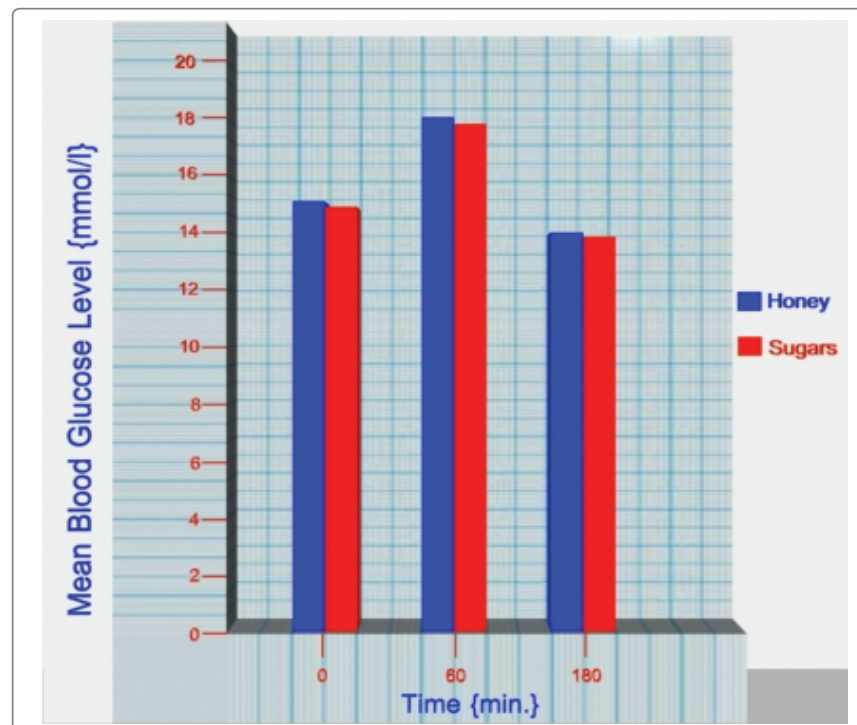

Figure 5: Mean Blood Glucose Level (mmol/l) Comparing the Effect of Low Doses ( 25 grams) of Honey and Sugars mixture Taken by Diabetic Patients $(n=21)$.

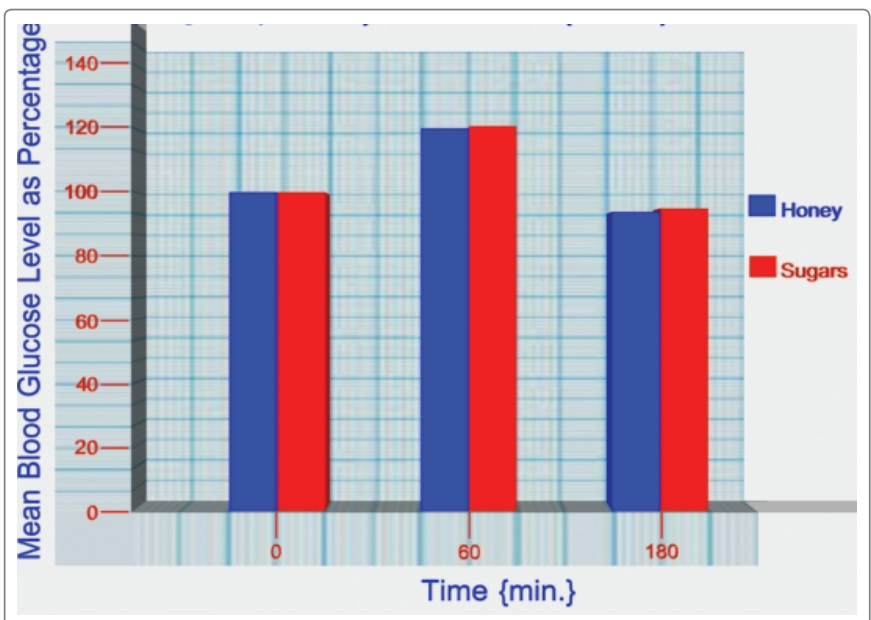

Figure 6: Mean Blood Glucose Level as Percentage (Fasting=100\%) Comparing the Low Doses of Honey and Sugars Mixture (25 grams) Taken by Diabetic Patients $(n=21)$.

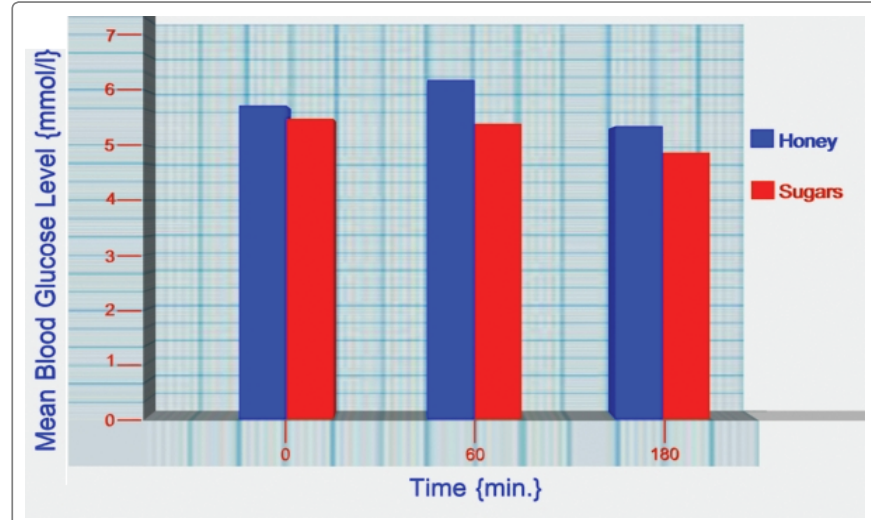

Figure 7: Mean Blood Glucose Level ( $\mathrm{mmol} / \mathrm{l})$ Comparing the Low Doses (25 grams) of Honey and Sugars mixture Taken by Non-diabetic Control $(n=10)$.

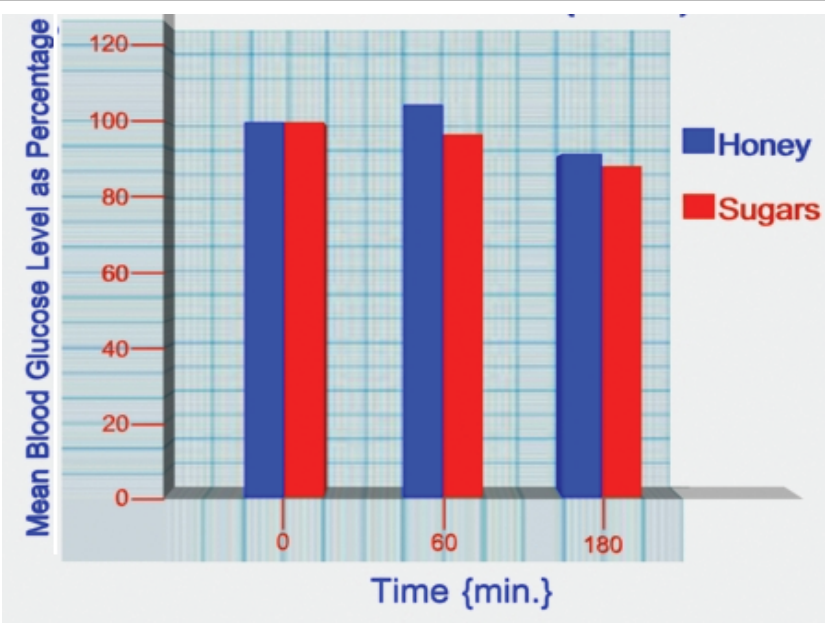

Figure 8: Mean Blood Glucose Level as Percentage (Fasting=100\%) Comparing the Low Doses (25 grams) of Honey and Sugars Mixture Taken by Non Diabetics Control $(n=10)$.

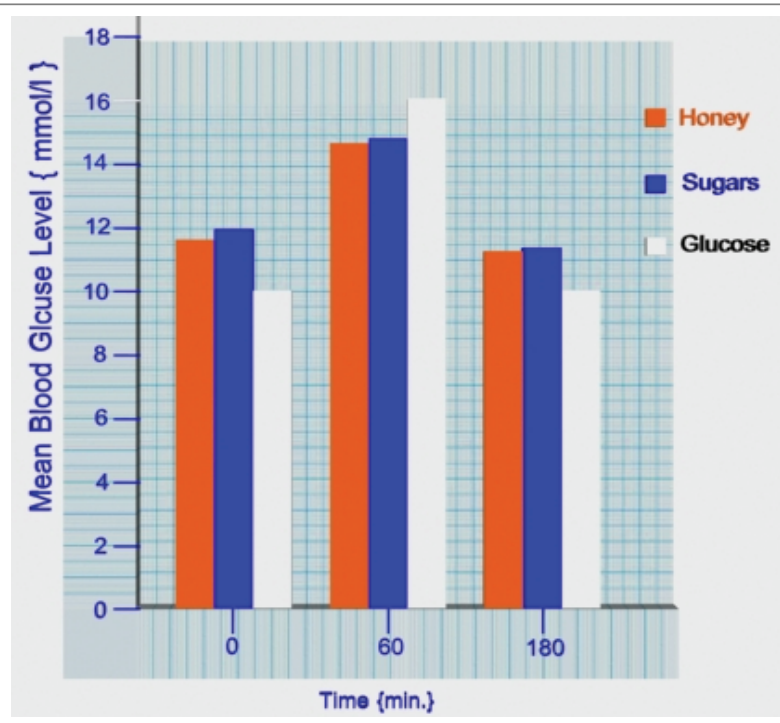

Figure 9: Mean Blood Glucose Level ( $\mathrm{mmol} / \mathrm{l}$ ) Comparing the Low Doses (25 grams) of Honey, Sugars mixture, and Glucose Taken by Diabetic Patients. 
(Then eat from all the fruits and follow the ways of your Lord laid down [for you]. There emerges from their bellies a drink, varying in colors, in which there is healing for people. Indeed in that is a sign for a people who give thought].

\section{Conclusion}

Bee honey at low doses (equivalent to $25 \mathrm{~g}$ sugars) decreases blood glucose level below the fasting level (after 3 hours). Thus, low doses of genuine honey (approximately 3 table spoons) can be recommended for diabetic patients as a sweetener, beside to its high nutritional value, instead of using the so-called diabetic food which offers no metabolic advantage and often have side effects.

Bee honey supplementation in individuals with impaired glucose tolerance or who are at pre-diabetic stage may delay or prevent the development of diabetes mellitus.

\section{Acknowledgement}

I would like to express my gratitude to my learned supervisor, Professor Mustafa Idris Albashir for his support and continuous advising. My indebtedness to my family, especially soul of my father, who supported and encouraged me to conduct this research. I extend my appreciation to my husband for encouraging me to publish this work. My gratefulness to the diabetic patients enrolled in this study and to the healthy volunteers shared as control.

\section{References}

1. Kumar PJ, Clark M (2002) Kumar and Clark's Clinical Medicine. Saunders, London 1099-1121.

2. Jahan S, Fariduddin M, Sultana N, Aktar Y, Hasan M, et al. (2015) Predictors of Post-Partum Persistence of Glucose Intolerance and its Association with Cardio-Metabolic Risk Factors in Gestational Diabetes Mellitus. J Diabetes Metab 6.

3. Chan-Rodríguez D, Ramón-Sierra J, Lope-Ayora J, Sauri-Duch E, Cuevas-Glory L, et al. (2012) Antibacterial properties of honey produced by Melipona beecheii and Apis mellifera against foodborn microorganisms. Food Sci Biotechnol 21: 905-909.

4. Zumla A, Lulat A (1989) Honey-A remedy rediscovered. J R Soc Med 82: $384-385$

5. Eteraf-Oskouei T, Najafi M (2013) Traditional and modern uses of natural honey in human diseases: a review. Iran J Basic Med Sci 16: 731-742.

6. Kassim M, Achoui M, Mustafa MR, Mohd MA, Yusoff KM (2010) Ellagic acid, phenolic acids, and flavonoids in Malaysian honey extracts demonstrate in vitro anti-inflammatory activity. Nutr Res 30: 650-659.

7. Feás X, Estevinho ML (2011) A survey of the in vitro antifungal activity of heather (Erica sp) organic honey. J Med Food 14: 12841288.

8. Zeina B, Othman O, Al-Assad S (1996) Effect of honey versus thyme on Rubella virus survival in vitro. J Altern Complement Med 2: 345348.

9. Tan HTT, Rahman RA, Gan SH, Halim AS, Hassan SA, et al. (2009) The antibacterial properties of Malaysian tualang honey against wound and enteric microorganisms in comparison to manuka honey. BMC Complement Altern Med 9: 1-8.

10. Fukuda M, Kobayashi K, Hirono Y, Miyagawa M, Ishida T, et al. (2011) Jungle Honey Enhances Immune Function and Antitumor Activity. Evid Based Complement Alternat Med 2011: 908743.
11. Egan H, Kirk RS, Sawyer R (1922) Person's Chemical Analysis of Foods. $8^{\text {th }}$ Edition, Edinburgh, Churchill Livingstone, USA.

12. Jenkins DJ, Wolever TM, Jenkins AL, Thorne MJ, Lee R, et al. (1983) The glycaemic index of foods tested in diabetic patients: a new basis for carbohydrate exchange favouring the use of legumes. Diabetologia 24: 257-264.

13. de Kalbermatten $N$, Ravussin $E$, Maeder $E$, Geser $C$, Jéquier $E$, et al. (1980) Comparison of glucose, fructose, sorbitol, and xylitol utilization in humans during insulin suppression. Metabolism 29: 62-67.

14. Topping DL, Mays PA (1976) Comparative effects of fructose and glucose on the lipid and carbohydrate metabolism of perfused rat liver. Brit J Nut 36: 113-126.

15. Hers HG, Stalmans W, Dewulf H, Laloux M, Hue L (1974) The control Of glycogen metabolism in liver. In: Lundquist F, Tygstrup $\mathrm{N}$ (eds) Regulation of hepatic metabolism. Copenhagen 237-249.

16. Henry RR, Crapo PA, Thorburn AW (1991) Current issues in fructose metabolism. Annu Rev Nutr 11: 21-39.

17. Pickup J, Williams $G$ (1998) Textbook of diabetes. $2^{\text {nd }}$ Edition, Blackwell Science.

18. loyrish N (1977) Bees and People. In: Creighton HC (eds) Bees and People. MIR, Moscow, Russia.

19. Al-Waili N (2003) Intrapulmonary administration of natural honey solution, hyperosmolar dextrose or hypoosmolar distill water to normal individuals and to patients with type-2 diabetes mellitus or hypertension: their effects on blood glucose level, plasma insulin and C-peptide, blood pressure and peaked expiratory flow rate. Eur J Med Res 8: 295-303.

20. Erejuwa OO, Sulaiman SA, Wahab MSA, Sirajudeen KNS, Salleh, et al. (2012) Hepatoprotective effect of tualang honey supplementation in streptozotocin-induced diabetic rats. Int J Appl Res Nat Prod 4: $37-41$.

21. Rakha MK, Nabil Zl, Hussein AA (2008) Cardioactive and vasoactive effects of natural wild honey against cardiac malperformance induced by hyperadrenergic activity. J Med Food 11: 91-98.

22. Erejuwa OO, Gurtu S, Sulaiman SA, Wahab MSA, Sirajudeen KNS, et al. (2010) Hypoglycemic and antioxidant effects of honey supplementation in streptozotocin-induced diabetic rats. Int J Vitam Nutr Res 80: 74-82.

23. Beretta G, Granata P, Ferrero M, Oriolia M, Facinoa RM (2005) Standardization of antioxidant properties of honey by a combination of spectrophotometric/fluorimetric assays and chemometrics. Anal Chim Acta 533: 185-191.

24. Erejuwa OO, Sulaiman SA, Wahab MSA, Sirajudeen KNS, Salleh S, et al. (2012) Honey Supplementation in Spontaneously Hypertensive Rats Elicits Antihypertensive Effect via Amelioration of Renal Oxidative Stress. Oxid Med Cell Longev 2012: 374037.

25. Utku N, Pape UF (2016) Neuroendocrine Tumors. J Mult Scler 3: 193.

26. Van Schaftingen E, Davies DR (1991) Fructose administration stimulates glucose phosphorylation in the livers of anesthetized rats. FASEB J 5: 326-330. 